DOI 10.7603/s40956-016-0003-3

Moroccan J. Pure and Appl. Anal.(MJPAA)

ERRATUM

Volume 2(1), 2016, Page 33

ISSN: $2351-8227$

\title{
Erratum to: A new Ostrowski type inequality for functions whose first derivatives are of bounded variation
}

\author{
HÜSEYIN BUDAK ${ }^{a}$ AND MEHMET ZEKI SARIKAYA ${ }^{a}$
}

Erratum to: Moroccan J. Pure and Appl. Anal.(MJPAA ), Volume 2(1), 2016, Pages 1-11, DOI: 10.7603/s40956-016-0001-5

The original paper (DOI 10.7603/s40956-016-0001-5) was written with erroneous symbols, which have not been displayed online correctly. The PDF has been replaced by a revised file including the correct symbols.

\footnotetext{
${ }^{a}$ Department of Mathematics, Faculty of Science and Arts, Düzce University, Düzce-TURKEY.
} e-mail: hsyn.budak@gmail.com,sarikayamz@gmail.com. 